\title{
Finding the right balance
}

\section{Immediate safety versus long-term social change}

\section{LOUISE EHLERS AND SEAN TAIT}

Open Society of SA

louise@ct.osf.org.za

South Africa has a reputation as one of the most violent societies in the world, despite the fact that overall levels of crime have consistently come down since 2001. In this and other developing countries, crime exacts a high cost in terms of health and security and has the potential to scupper the attempts of governments to fulfil their responsibilities in addressing poverty and inequality. ${ }^{1}$ This article argues that there is an urgent need to develop policies that balance the immediate need for safety and security with the long-term objective of achieving systemic social change. It describes an intervention undertaken by the Open Society Foundation for South Africa in collaboration with three provincial departments of Safety and Security that aims to explore ways in which a dual approach of keeping citizens safe in the context of current levels of crime, and simultaneously developing models for long term crime reduction, can be achieved.

The recently published book: Action for a Safe South Africa offers us a vision of a society in which:

- Our children play safely in beautiful parks

- Our women walk easily to and from work

- Our public transport system offers safe passage to local and foreign tourists

- Our pavement cafes flourish and sound with relaxed laughter

- Our townships and suburbs reflect the amazing spirit of our people

- Our rural roads offer us the amazing vistas of our beautiful country ${ }^{2}$

A wonderful vision, indeed. In stark contrast, however, our country still faces serious challenges from unacceptably high levels of serious and violent crime. The June 2008 South African Police Service national crime statistics ${ }^{3}$ cemented South Africa's reputation as one of the most violent societies in the world, despite the fact that overall levels of crime have consistently come down since 2001. In this and other developing countries, crime exacts a high cost in terms of health and security and has the potential to scupper the attempts of governments to fulfil their responsibilities in addressing poverty and inequality.

In this context there is an urgent need to explore, understand and navigate the continuum between criminal justice (and the role of the state), crime prevention, and the struggle to adhere to international human rights norms and standards. In doing this we need to address a combination of 
theoretical and practical questions in relation to criminal justice, such as: How do we negotiate the tension between the project to promote safety and the project to promote democracy? In other words, how does one ensure the safety of the citizenry without a concomitant negative impact on its right to the free and unfettered enjoyment of political and civil liberties? What are the main social and political processes that initiate and drive change in criminal justice systems?

Current concerns in South Africa include the introduction of increasingly repressive criminal justice legislation; decreasing levels of access to information held by criminal justice agencies (notwithstanding enabling legislation offering the contrary); and the weakening of institutions established for the purposes of promoting human rights (e.g. the Human Rights Commission).

\section{SOUTH AFRICA'S APPROACH TO MANAGING THE CRIME PROBLEM}

Crime prevention ${ }^{4}$ is recognised internationally as a key component, along with law enforcement, of an effective response to promoting safety. ${ }^{5}$ In South Africa, however, despite having one of the highest crime rates ${ }^{6}$ in the world, our support for crime prevention has been patchy at best. ${ }^{7}$ In contrast, strengthening the criminal justice response to crime has been the focus of consistent attention over the 14 years post apartheid. The criminal justice budget has grown from R14 billion in 1995 to R71 billion in 2009. ${ }^{8}$ South Africa's per capita spending on criminal justice (USD 130) is double the international average. ${ }^{9}$

While this investment may have contributed to the rates of recorded crime in most categories decreasing since 1995 (with murder down from its high of 67,9 per 100000 to 38,6 per 100000 in 2008), this has not ensured a safe, secure and peaceful environment for citizens. In addition to being very expensive in monetary terms, the primary focus on law enforcement as the way to counter crime and ensure safety has resulted in an increasingly militarised society. This is demonstrated by the fact that police numbers are set to increase (again) from the already high current level of 183000 to over 200000 by 2012, making South Africa a country with one of the largest police agencies under single command in the world. Yet, despite this, South Africans spend ever greater amounts on private security. It is estimated that the R14 billion private security industry employs 300000 active registered security guards. ${ }^{10}$

Besides growing the police service, other measures have been introduced to counter crime, such as minimum sentences and restrictive bail conditions. This has resulted in an extremely high prison population: with 164957 inmates our prisons are hugely overcrowded, with all the concomitant problems. South Africa's incarceration rates are among the highest in the world. Approximately 350 in every 100000 South Africans are in prison. ${ }^{11}$

In much the same way as the state has responded to high levels of crime by increasing punitive measures, citizens too have hardened their attitudes to crime over the past six years. The number of South Africans who believe that social development should be prioritised to address property crime fell from 62 per cent in the 2003 ISS National Victim Survey to 52 per cent in 2007. Corroborating this, both the 2003 and 2007 surveys show that because South Africans increasingly perceive crime to be motivated by greed rather than real need, their response is to suggest that there is a need to increase the punitive response to crime rather than to spend on social development. ${ }^{12}$

Yet, despite the massive amount spent on law enforcement by the state, South Africans do not feel safer. The 2007 victim survey also confirmed a steady decline in perceptions of safety since 1998. Almost 60 per cent of interviewees for the 2007 survey felt crime levels had increased over the past four years with fewer people reporting feeling safe walking around their neighbourhood. ${ }^{13}$

Jody Kollapen, chairperson of the South African Human Rights Commission, notes, 
If anything, this [punitive] stance has exacerbated an over-reliance on criminal justice processes in responding to the social ills of the nation. A more balanced approach - one that recognises the need to protect society but also the necessity to advance social cohesion and development must be adopted. ${ }^{14}$

He goes on to argue that while we need to retain the capacity to protect society against those who represent a threat, we should guard against the tendency to overextend the criminal justice system and the expectation that it should remedy problems brought about by poverty and inequality. ${ }^{15}$

Similarly, Marc Mauer, director of the Sentencing Project in Washington DC, argues that one cannot place crime prevention and law enforcement at opposite ends of the spectrum in an either/or situation. He makes the point that the discussion about how to reduce crime has become polarised between advocates of long-term solutions versus those who seek immediate results, and points out that this is not a useful dichotomy.

\footnotetext{
On the one hand, we would be foolish to believe that we can create a fair and just society without addressing systemic issues such as poverty and racism. However, if we only wait until those issues are resolved, we will fail to meet the urgent needs of improving safety on a daily basis. In this regard, we need to seek models of programmes and policies that can provide short-term benefit while building constituencies and approaches for longterm systemic change. ${ }^{16}$
}

The classic example of this polarisation in South Africa is the demise of the National Crime Prevention Strategy (NCPS). Drafted in 1996, the NCPS explored an approach to addressing crime and violence that sought to understand and address the social, economic and historical drivers behind the crime and violence plaguing the country. In doing so it created a framework within the spirit of the Reconstruction and Development Programme of supporting interventions that would address the risk and resilience factors associated with many crime types, ultimately seeking to prevent them.
By 1999 the NCPS was for all intents and purposes, shelved in a series of developments that clearly demonstrated the ascendance of the law enforcement agenda. These included the downgrading of the National Secretariat for Safety and Security, the lead agency in the development of the strategy, its absorption into the police, and the rising dominance of the National Crime Combating Strategy of the SAPS. The nonimplementation of the subsequent 1999 White Paper on Safety and Security, which gave specific policy direction to many of the aspects of the NCPS, and the fact that it has since lapsed, effectively shut the strategy down in all but name.

Commenting six years later, Frank refers to a legacy characterised by lack of clarity in government about crime prevention, the devastating impact of a lack of skills and capacity in expanding the quality and reach of social crime prevention interventions, and the inability of the country to make use of key leverage points, in particular investing in children from an early age. $^{17}$

Despite the policy direction that government has taken since 1994, the discourse on managing crime has to some extent matured in recent years and has started to acknowledge the role of both law enforcement and crime prevention in making South Africans safe. Networks of civil society practitioners such as Action for a Safe South Africa have continued to mobilise around the prevention agenda, while government has also developed and facilitated some efforts at promoting a prevention agenda, ranging from Urban Renewal to provincial Crime Prevention Strategies.

In his 2009 budget speech Trevor Manuel announced a significant increase in social spending. The largest adjustments to spending plans go to poverty reduction: $\mathrm{R} 25$ billion has been added to provincial budgets, mainly for education and health care, and R13 billion for social assistance grants and their administration. $\mathrm{R} 4$ billion has been added to the school nutrition programme and R2, 5 billion to municipalities for

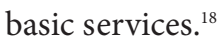


Meanwhile, considerable knowledge has been built up by civil society practitioners in a range of prevention fields, including efforts to address alcohol and drug abuse, promote diversion, support early childhood development, improve safety at schools, develop sport and recreational facilities, and support young mothers and families at risk.

The challenge for many, however, remains how this new knowledge can be brought to scale and attract considered state investment over the time periods required to demonstrate results. The balancing act for the state right now is one of keeping citizens safe against the backdrop of high levels of serious and violent crime while simultaneously providing committed resources and support to long-term social change.

Commentators such as Dixon ${ }^{19}$ warn against conflating crime prevention and social policy - he argues that issues like appropriate and adequate recreational facilities should be prioritised and addressed in their own right and should not only receive attention because of a possible link to their crime prevention utility. This said, efforts to mitigate and respond to crime go beyond the mandate of the police and must logically make the link between crime prevention and social spending. Social crime prevention must be a priority that is integrated across a range of government departments, most immediately the departments of social development and education.

\section{THE OSF-SA PROJECT}

Over the past ten years the Open Society Foundation for South Africa (OSF-SA), has invested extensively in building knowledge in crime prevention in the fields of school safety, violence against women, and local safety. The Foundation is motivated by the fact that the results of a singular law enforcement approach have been mixed at best, and the increasingly punitive stance adopted by criminal justice role players could exacerbate underlying social and economic issues that contribute to the high levels of crime in South African society. It has therefore employed the lessons emerging from its past work in the development of a new strategy to support crime prevention in three communities in South Africa.

The multi-year 'Crime and Safety Project' includes a substantial component on evaluating safety. It is also an attempt to show that effective partnerships between government communities and civil society are essential for crime prevention. The programme is informed by the 2002 United Nations Guidelines for Crime Prevention $^{20}$ and its eight core principles, namely:

- Government leadership

- Socio-economic development and inclusion

- Cooperation and partnership

- Sustainability and accountability

- Knowledge base

- Human rights and rule of law

- Interdependency

- Differentiation (recognising the different needs of communities and sectors of the community)

OSF-SA is working in partnership with provincial governments in three provinces and has signed Memoranda of Understanding (MOUs) with the Department of Community Safety in Gauteng, the Eastern Cape and the Western Cape. These MOUs outline the roles and responsibilities of each party in the implementation of the project in three sites that were identified by the provinces as being 'crime hotspots'; namely Orange Farm in Gauteng, Nompumelelo in the Eastern Cape, and Elsie's River in the Western Cape.

\section{ORANGE FARM, NOMPUMELELO AND ELSIE'S RIVER}

The three sites are diverse in terms of size, demographics, structural design and social context. However, they share many common problems, including poverty, underdevelopment, high rates of HIV/AIDS and social and economic inequities. 


\section{Orange Farm}

Orange Farm is one of the largest townships in South Africa. Located 45 kilometres south of Johannesburg, with an estimated population of one million, it is often referred to as one of the most indigent urban settlements in South Africa. Today the township is still considered to be fairly underdeveloped with the majority of residents facing significant socio-economic challenges, despite considerable infrastructural investments (e.g. the building of the new police station, railway station and victim support centre) over the past years. Recent statistics show that no less than 40 per cent of the population is under the age of 18 years and that many do not have access to proper health care, education and recreational facilities. Consequently a substantial proportion of these young people are said to engage in crime and violence as well as substance abuse.

Reportedly high numbers of teenage pregnancies and HIV/AIDS infection are further obstacles to the development of the Orange Farm community.

Against this backdrop the dichotomy of crime prevention and law enforcement is clearly illustrated. Policing strategies to arrest intoxicated teenagers for being drunk in public has served to keep them safe over periods when they are vulnerable to victimisation, but vital access to treatment and support to address the dangers of substance abuse is lacking, causing residents and police to repeat the same patterns of binge drinking and arrest weekend after weekend.

\section{Nompumelelo}

Nompumelelo by contrast is a small settlement located within the relatively wealthy suburb of Beacon Bay in urban East London in the Eastern Cape. The township has come a long way from its informal beginnings and has seen significant development of low-income housing. However, its history as a temporary abode for those who wanted to be nearer to their places of employment continues to haunt it. The population swells by thousands during the week.
These weekday migrants place a considerable burden on an already overstretched infrastructure; have a negative impact on community cohesion (which was demonstrated in residents' response to the safety audit); and are an eager market for the thriving shebeens.

\section{Elsie's River}

Elsie's River is located approximately 12 kilometres from the Cape Town city centre and has an estimated population of 150 000. A large proportion of the area consists of low-income housing such as council flats and semi-detached homes, and the area is characterised by overcrowding. It is also estimated that 34 per cent of the population is unemployed and that the majority of people who are employed are lowincome earners. Elsie's River is renowned for its gang activity and high levels of crime.

Elsie's River, like Orange Farm (and unlike Nompumelelo), has seen significant support for social crime prevention. It was the site of the Cape Flats Renewal Strategy, which introduced a comprehensive programme of environmental and social programmes. Unfortunately its legacy is largely a monument to our wavering and often fickle support for crime prevention, as the plans and interventions have not been evaluated or followed up. Initial efforts have been superseded by ever-new strategies aimed at social transformation and gang reduction, making the design of any subsequent intervention a painstaking task of sifting through what has been done, what has been achieved and where value can be added.

\section{HOW TO CREATE A VIABLE AND REALISTIC SAFETY PLAN?}

In light of the significant challenges outlined above, OSF-SA opted for a considered, methodical approach to this work. In keeping with the tested methodology of basing the intervention on evidence and knowledge, safety audits were undertaken at each of the sites. ${ }^{21}$ 
The researchers doing the safety audit were required to be mindful of all elements of a crime; namely the offenders, the victims, and the locations in which crimes take place. Qualitative and quantitative research methods were used to collect data and statistical information; complemented by well-placed interviews and focus group discussions with community groups.

In particular the audit provided for:

- The profile of the community (location, demographics etc)

- The nature and level of recorded crime in the identified community

- The specific safety concerns in the community

- The state resources available to address these concerns

- Current non-state resources to address these concerns

- Current interventions, the impact of these interventions and the challenges still faced

- A database of stakeholders and role players in the community as well as the institutional mechanisms in place to support broad multistakeholder safety initiatives

The information captured during the audits has had a dual utility. It has elicited from the range of partners, the buy-in and commitment necessary for successful implementation, and it has also provided baseline data for subsequent evaluations in each of the sites. Unsurprisingly, the findings from the audits support the need for a broad approach to addressing crime that encompasses not only the transformation of criminal justice institutions, but also changing public attitudes towards crime and addressing the underlying socio-economic factors that feed both crime and perceptions on the acceptability of crime.

Working with the audits, OSF-SA has set about developing detailed site-specific safety plans. This has been done in collaboration with a multidisciplinary project team of community members and local and provincial government departments at each site. In many ways the teams mirror the multi-disciplinary Community Safety Forum structures currently being mooted by government as a potential vehicle for crime prevention delivery.

While many of the interventions identified in the plans fall squarely within the mandate of local stakeholders, OSF-SA will use its grant-making capacity to support civil society interventions that are aimed at meeting some of these objectives. Even here, multi-utilities are being sought. Not only will the investments seed the safety plans, but the lessons for government in working with civil society to implement aspects of the strategy will be particularly useful in understanding the elements of successful partnerships, and integrating the experience and expertise of civil society into general government service delivery. Success in this instance is defined by targeted, sustainable support that meets defined objectives of a safety strategy with measurable impact.

\section{THE PAUCITY OF ROBUST LONGITUDINAL EVALUATION DATA}

A weakness in South Africa's growing knowledge and understanding of crime prevention is the paucity of robust evaluation and particularly longitudinal evaluations tracking progress over time. This in turn has an impact on the development of policy to promote crime prevention as a viable strategy for making South Africa safe. Recognising this, and as a part of its contribution to developing knowledge on crime prevention, law enforcement and safety, the OSFSA has introduced a parallel component to the project: the development and implementation of a longitudinal evaluation across all three sites.

As the first step in setting up the evaluation system, a comprehensive set of safety indicators is being developed and tailored to the needs of each of the provinces and individual sites, stakeholders and service providers. This individualised tailoring for role players will allow various service providers, for example health services or the police, to track and report on their progress towards implementing the safety plan in a manner that feeds into a system for tracking progress across the safety plan generally. Using these 
indicators, an assessment will be undertaken of the crime and safety project at each of the sites on an annual basis. This will provide the foundation for a detailed longitudinal evaluation of the intervention and impact over time. Importantly, the indicators will be constructed off a generic template that will allow for an easy transfer of the methodology to other sites.

The development and implementation of a sound monitoring and evaluation system will have value both for the evaluation of the impact of the safety plans in Orange Farm, Elsie's River and

Nompumelelo, but also, more importantly, for the future management of safety strategies more broadly. Through the implementation of a sound monitoring system the OSF-SA hopes to be able to clearly demonstrate the utility of a crime prevention approach alongside that of law enforcement.

\section{CONCLUSION}

International research tells us that efforts to mitigate and respond to crime must be balanced by longer-term systemic changes aimed at addressing the causes and drivers of crime. Bringing about these changes goes beyond the mandate of the police, to encompass a range of stakeholders and disciplines. Social crime prevention must be a priority that is integrated across a range of government departments, most immediately the departments of social development and education.

If we look at efforts to promote diversion, build safety at schools and expand our social support networks, it can be said that significant progress has been made. We need to support these efforts consistently over time and ensure that interventions are evaluated so that we can understand the type and level of impact being made and adjust our strategies accordingly. We should put behind us the days of simply replacing one five-year crime prevention strategy with another. Rather, we need to evaluate the successes and challenges of our efforts and learn from the experience. The wealth of knowledge in civil society can make a significant impact if effectively supported. It is in this area that the OSF-SA project can provide new insights.

\section{NOTES}

1 J Irish-Qhobosheane, See no evil, hear no evil, the social economy of organised crime in Mozambique, SAIIA, 2008.

2 What every South African can do to build a safe community, Action for a Safe South Africa, SOUTH AFRICA - the Good News (Pty) Ltd, December 2008, 25.

3 See http://www.saps.gov.za/statistics/reports/crimestats/ 2008/crime_stats.htm (accessed February 2009).

4 L Sherman, Thinking about crime prevention, in D Gottfredsen, L Sherman, D MacKenzie et al, Crime, what works, what doesn't, what's promising, University of Maryland, 1996. Sherman makes the point that the debate over crime often treats 'prevention' and 'punishment' as mutually exclusive concepts, polar opposites on a continuum of 'soft' versus 'tough' responses to crime. He says: 'The science of criminology, however, contains no such dichotomy. It is as if a public debate over physics had drawn a dichotomy between flame and matches. Flame is a result. Matches are only one tool for achieving that result. Other tools besides matches are well known to cause fuel to ignite into flame, from magnifying glasses to tinder boxes. Similarly, crime prevention is a result, while punishment is only one possible tool for achieving that result.' This paper argues that there needs to be a balance between these various tools.

5 Guidance on local safety audits, European Forum for Urban Safety, 2007.

6 The murder rate at 38,6 per 100000 population is far in excess of an international average of five per 100000 . See J Burger and H Boshoff, The state's response to crime and public security in South Africa, ISS Research Report, Pretoria: ISS, 2008, http://www.issafrica.org/dynamic/ administration/file_manager/file_links/STATECRIME.PD F?link_id=24\&slink (accessed February 2009).

7 See C Frank, The role of education, health and social development in preventing crime, ISS Monograph 126 October 2006.

8 National Treasury. Estimates of national expenditure 2009, Pretoria: National Treasury, 2009.

9 In 2005 South Africa spent US $\$ 130.00$ per person on criminal justice, compared to an average by the rest of the world of US\$ 66.00. See A Altbeker, Paying for crime: South African spending on criminal justice, ISS Occasional Paper 115, Pretoria: ISS, July 2005.

10 R Taljaard, Private and public security in South Africa, ISS Monograph 146, Pretoria: ISS, July 2008.

11 International research indicates that rates of incarnation have no significant impact on levels of crime - see M Tonry, Crime does not cause punishment, Keynote address at the OSF-SA Conference on Sentencing in South Africa, Sentencing in South Africa conference report, Open Society Foundation for South Africa, 2006, 4-6.

12 R Pharoah, National Victims of Crime Survey, ISS Occasional Paper 175, Pretoria: ISS, December 2008.

13 Pharoah, National Victims of Crime Survey. 
14 J Kollapen, Approach to crime fails democracy, Mail and Guardian 22-28 June 2007.

15 Kollapen, Approach to crime fails democracy.

16 See the OSF-SA conference report: Sentencing in South Africa, October 2006.

17 Frank, The role of education, health and social development in preventing crime.

18 Budget Speech 2009 by the Minister of Finance, Trevor A Manuel, available at http://www.info.gov.za/speeches/ 2009/09021114561001.htm (accessed February 2009).

19 B Dixon, Development, crime prevention and social policy in post-apartheid South Africa, Critical Sociology, 26(1), 2006, 169-191.

20 UN Economic and Social Council Action to promote effective crime prevention, Guidelines for crime prevention UN ECOSOC, July 2002.

21 The safety audit is an important tool in reaching a common understanding on crime and its causes in a particular area. See Making South Africa safe, a manual for community based crime prevention and guidance on local safety audits, European Forum for Urban Safety, 2007. 